\title{
Uso dos Métodos VLF e Eletrorresistividade na Caracterização do Modelo Fenda de Acumulação de Água Subterrânea em Terrenos Cristalinos: Exemplo da Fazenda Tararaca/RN
}

Jesimael Avelino da Silva1 ${ }^{1}$, Walter Eugênio de Medeiros², Emanuel Ferraz Jardim de Sá2, Carlos César Nascimento da Silva², Josibel Gomes de Oliveira Júnior².

${ }^{1}$ Departamento de Polícia Federal, ${ }^{2}$ UFRN

Copyright 2021, SBGf - Sociedade Brasileira de Geofísica

This paper was prepared for presentation during the $17^{\text {th }}$ International Congress of the Brazilian Geophysical Society held in Rio de Janeiro, Brazil, 16-19 August 2021.

Contents of this paper were reviewed by the Technical Committee of the $17^{\text {th }}$ International Congress of the Brazilian Geophysical Society and do not necessarily represent any position of the SBGf, its officers or members. Electronic reproduction or storage of any part of this paper for commercial purposes without the written consent of the Brazilian Geophysical Society is prohibited.

\section{Abstract}

The integrated use of geophysical methods and classic methodologies for the location of wells in crystalline terrain allowed to characterize the model of groundwater accumulation on the Tararaca farm, in Santo Antônio/RN. Three VLF profiles and three apparent resistivity sections were surveyed to investigate the presence of fractures zones in the study area. The resistivity sections were obtained with the Schlumberger arrangement and the VLF profiles tuned the stations NAA (frequency of $\mathbf{2 4 . 0}$ $\mathrm{kHz}$ ) and $\mathrm{GBZ}$ (frequency of $19.6 \mathrm{kHz}$ ). The interpretation of the data showed that the main creek does not present evidence of control by a fracture zone. In fact, it appears to be controlled by the foliation of the gneisses that emerge in the area. On the other hand, the secondary creak is controlled by fractures, thus being an example of the groundwater accumulation model of the type 'fracture-creek" ("riacho-fenda").

\section{Introdução}

A locação de poços no cristalino geralmente segue uma metodologia tradicional, onde o modelo do "riacho-fenda", apresentado por Siqueira $(1963,1967)$, é bastante empregado. Nessa metodologia, são enfatizados os critérios estruturais (baseados principalmente em imagens aéreas) e de geologia de superfície, onde se tenta identificar zonas intensamente fraturadas, na maioria das vezes com riachos encaixados. Em algumas situações, problemas com coberturas sedimentares e a escala desfavorável das imagens aéreas dificultam precisar o local exato das zonas de fratura, o que aliado às incertezas da presença de água nas fraturas, são em boa parte responsáveis pelo baixo índice de acerto nas locações dos poços, podendo ser minimizado por meio do emprego da geofísica (e.g. Medeiros, 1987).

Neste trabalho apresentamos os resultados de um levantamento geofísico realizado com os métodos da eletrorresistividade e VLF, cujo objetivo é contribuir na discussão de modelos que condicionam o acúmulo de água no cristalino, em particular o modelo riacho fenda (Silva, 2000).

A área de trabalho está localizada na Fazenda Tararaca (município de Santo Antônio/RN) e apresenta um relevo ondulado onde são observados, de forma espaçada, grandes afloramentos de rocha cristalina. A litologia dominante no local é um ortognaisse granodiorítico a granítico, o qual apresenta-se localmente migmatizado. Ainda é possível encontrar pequenos veios pegmatíticos. A foliação do gnaisse apresenta direção NE-SW e mergulho de $30^{\circ}$ para noroeste. As fraturas identificadas nos afloramentos mostram direção dominantemente NW$\mathrm{SE}$, com única fratura na direção NE-SW. Dois riachos estão presentes na área estudada. $O$ riacho principal possui direção NE-SW, enquanto que o riacho menor tem direção NW-SE (Figura 01).

No local foi perfurado um poço, cujo critério para locação foi a confluência entre os dois riachos, os quais poderiam estar controlados por zonas de fraturas. A ficha de descrição da perfuração do poço desta localidade não foi encontrada.

\section{Métodos}

Foram levantados dados de resistividade e VLF em três linhas de medidas (transversais 01, 04 e 05), aproximadamente perpendiculares aos riachos, para investigar a presença de zonas de fraturas (Figura 01). A transversal 01 corta o riacho menor, enquanto as transversais 04 e 05 atravessam o riacho principal. As seções de resistividade aparente foram obtidas com o arranjo Schlumberger, separação entre estações de $20 \mathrm{~m}$ e aberturas $A B / 2$ de $2,5,10,20$ e $50 \mathrm{~m}$ ).

$\mathrm{O}$ perfil de VLF na transversal 01 foi realizando utilizando como fonte a estação NAA (frequência de $24,0 \mathrm{kHz}$ ), enquanto o perfis 4 e 5 sintonizaram a estação GBZ (frequência de 19,6 kHz). Em todos os perfis as medidas foram obtidas a cada $5 \mathrm{~m}$. O filtro linear utilizado foi proposto por Karous \& Hjelt (1983). Note-se que os perfis de VLF são adimensionais, como resultado da normalização em relação ao campo primário e são expressos em percentual.

\section{Resultados}

A seção de resistividade associada à transversal T1(Figura 02) mostra na sua na porção nordeste um brusco aumento da resistividade aparente. Esta resposta está relacionada à presença da rocha cristalina que está aflorando próximo à estação $40 \mathrm{~m}$. Adicionalmente, este 
contraste de resistividade se prolonga em profundidade e pode ser associado a presença expressiva de uma falha ou concentração de fraturas. Nas estações $0 \mathrm{~m}$ e $-50 \mathrm{~m}$, observam-se rebaixamentos nas linhas de isovalores de resistividade aparente para as maiores aberturas de $A B / 2$, sendo mais pronunciado o rebaixamento da estação $0 \mathrm{~m}$. Este comportamento pode estar relacionado à presença de duas zonas de fraturas.

O perfil de VLF da transversal 01 (Figura 03) indica dois picos anômalos nas proximidades das estações $0 \mathrm{~m}$ e $50 \mathrm{~m}$, respectivamente, indicando tratar-se de feições mais condutivas. Ambas as anomalias de VLF corroboram as anomalias de baixa resistividade aparente presentes nas posições $0 \mathrm{~m}$ e $-50 \mathrm{~m}$ da seção de resistividade (Figura 02), mostrando que a interpretação da existência de duas zonas de fratura é consistente.

Para investigar à possível presença de fraturas junto ao riacho principal, foram levantadas as transversais 04 e 05 . A seção de resistividade aparente da transversal 04 (Figura 04) apresenta os maiores valores na porção sudeste. O centro do riacho, coincidente com a estação 0 $\mathrm{m}$, apresenta um leve rebaixamento da resistividade aparente (curva de 120 Ohm.m), possivelmente associado à presença de aluvião arenoso de reduzida espessura. No geral, a seção não apresenta indícios de fraturamento.

A transversal 05 (Figura 06) também apresenta valores altos de resistividade aparente na porção sudeste (entre as estações $20 \mathrm{~m}$ e $40 \mathrm{~m}$ ). No setor noroeste da seção, as linhas de isovalores de resistividade aparente estão sub-horizontais, entretanto com altos valores de resistividade, indicando que o cristalino está subaflorante. Observa-se que os menores valores de resistividade aparente estão localizados próximos ao centro do riacho (entre as estações $0 \mathrm{~m}$ e $20 \mathrm{~m}$ ). Os perfis de VLF sobre as transversais 04 (Figura 05) e 05 (Figura 07) também apresentam anomalias localizadas entre as estações $0 \mathrm{~m}$ e $20 \mathrm{~m}$, consistentes com os dados de resistividade no centro do riacho.

Com base nas descrições dos afloramentos e nos dados geofísicos disponíveis, constata-se que o modelo de riacho-fenda está bem caracterizado no riacho menor com direção NW, ou seja, esse riacho encontra-se encaixado numa zona de fratura. Os fatos que embasam esta interpretação são: i) a presença nos afloramentos de fraturas com a mesma direção do riacho, sendo que estruturas similares são também observadas nas imagens aéreas do local; ii) a coincidência e alinhamento das anomalias geofísicas, em especial, nos dados da seção de resistividade aparente e de VLF. Por outro lado, o riacho principal, que possui direção NE, não apresenta feições que possam indicar o seu controle por uma zona de fratura. Por outro lado, nota-se o seu paralelismo com a foliação dos gnaisses no local, que é um indício de que a direção do riacho está controlada pela direção da foliação.

\section{Conclusões}

O uso integrado de métodos geofísicos e de metodologias clássicas para locação de poços em terreno cristalino permitiu caracterizar o modelo de acúmulo de água subterrânea na Fazenda Tararaca, município de Santo Antônio/RN. Por meio de imagens aéreas foram identificadas fraturas com a mesma direção de um pequeno riacho existente no local. Por outro lado, o riacho principal (direção NE), não apresenta evidências de controle por uma zona de fratura, apesar do seu paralelismo com a foliação dos gnaisses que aflora na área. Adicionalmente, a interpretação dos dados geofísicos indica forte relação entre as anomalias observadas nas seções de resistividade aparente e nos perfis de VLF, permitindo caracterizar o modelo para de acúmulo de água subterrânea na Fazenda Tararaca como riacho-fenda.

\section{Agradecimentos}

Os autores agradecem as discussões e participação de Ana Catarina Fernandes Coriolano e Elmo Marinho de Figueiredo (ex-CDM/RN) nos trabalhos de campo. Este trabalho foi financiado pelo programa PADCT3, junto com bolsas do CNPq e CAPES, concedida aos autores.

\section{Referências}

KAROUS, M \& HJELT, S.E. 1983. Linear filtering of VLF dip-angle measurements. Geophysical Prospecting, 31. 782-794.

MEDEIROS, W.E, 1987. Eletro-resistividade aplicada à hidrogeologia do cristalino: um problema de modelamento bidimensional. Universidade Federal da Bahia, Salvador, BA. Dissertação de Mestrado. 149p.

SILVA, J.A. 2000. Estruturas de acumulação de água subterrânea em rochas cristalinas: estudo geofísico e geológico de casos no Estado do Rio Grande do Norte. Dissertação de Mestrado, PPGG/UFRN.

SIQUEIRA, L. 1963. Contribuição da geologia à pesquisa da água subterrânea no cristalino. SUDENE, Recife, 51p.

SIQUEIRA, L. 1967. Contribuição da geologia à pesquisa da água subterrânea no cristalino. Água Subterrânea, Recife, 2(9):1-29.jan/mar. 


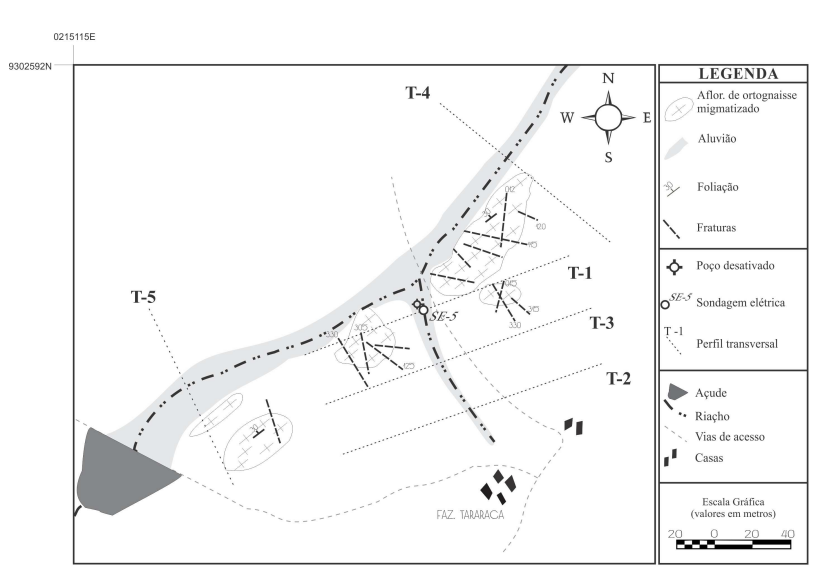

Figura 01 - Fazenda Tararaca: mapa de situação mostrando a disposição dos afloramentos, fraturas e riachos, além das linhas de medidas geofísicas.

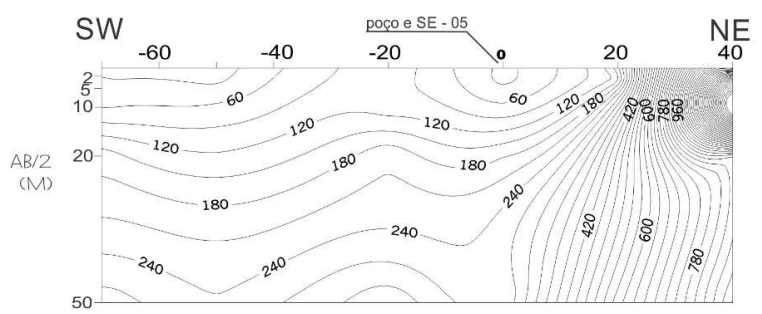

Figura 02 - Seção sobre a transversal T1, realizada próxima ao poço, arranjo Schlumberger.

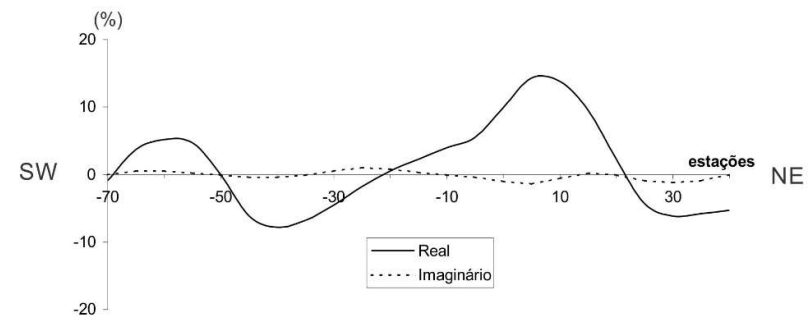

Figura 03 - Perfil de VLF da transversal 01.

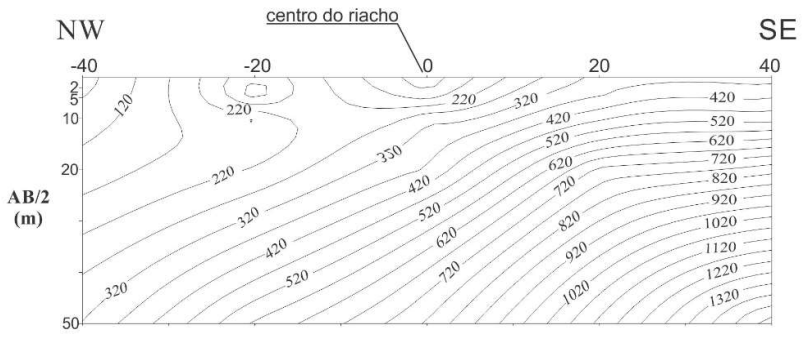

Figura 04 - Seção de resistividade aparente da transversal 04. Valores em Ohm.m. arranjo Schulumberger.

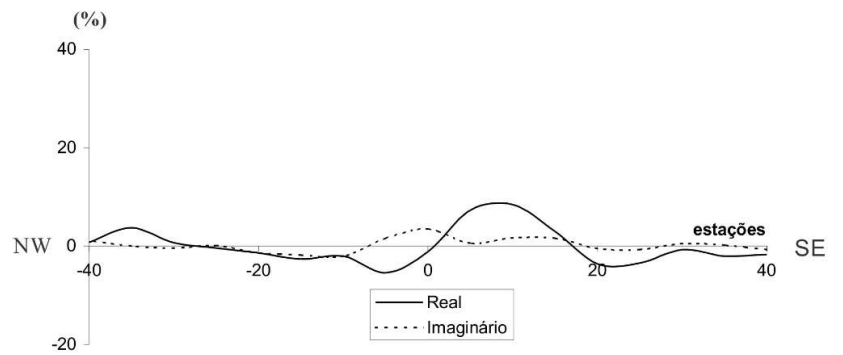

Figura 05 - Perfil de VLF da transversal 04.

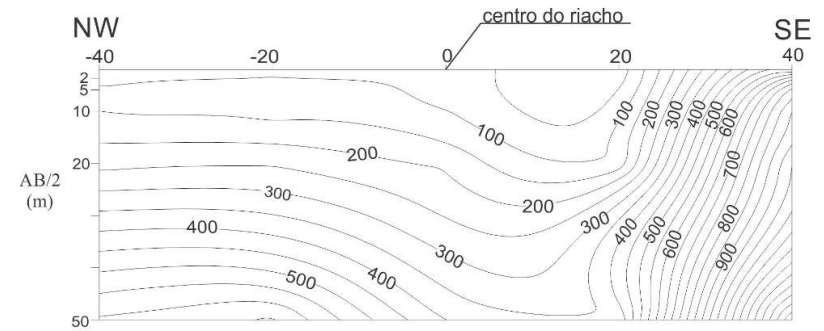

Figura 06 - Seção de resistividade aparente da transversal 05 . Valores em Ohm.m. arranjo Schlumberger.

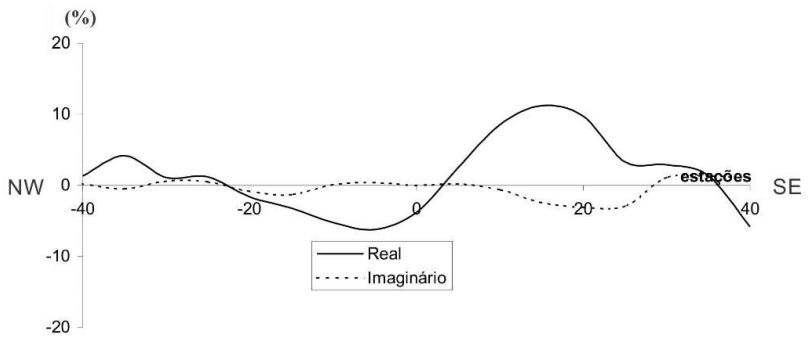

Figura 07 - Perfil de VLFda transversal 05. 